\title{
Integrating Health Education into Clinical Settings
}

\author{
Theresa L. Byrd ${ }^{1}$, Mary M. Hoke², Nell H. Gottlieb ${ }^{3}$ \\ ${ }^{1}$ University of Texas Houston School of Public Health-El Paso \\ ${ }^{2}$ New Mexico State University \\ ${ }^{3}$ University of Texas at Austin
}

\begin{abstract}
The Clinic Health Education and Lifestyle Promotion (Clinic HELP) Initiative, funded by the Paso del Norte Health Foundation, was designed to extend health education services to medically indigent residents along the US-Mexico border. This paper reports finding of an evaluation that examined the integration of health education into community clinics, and the quantity and quality of health education services delivered. We found that start-up funding, appropriate training, guidance from technical experts, clearly communicated expectations, and having a strong program champion combined with health educator/health agency "fit" can facilitate the integration process.
\end{abstract}

(c) 2007 Californian Journal of Health Promotion. All rights reserved.

Keywords: health education, clinical settings, program integration

\section{Integrating Health Education into Clinical Settings}

In the US-Mexico border region, as in other parts of the United States, chronic diseases have become the major causes of disease burden (Remington et al., 1988). The US-Mexico border is unique because of its blend of cultures, customs, and languages, and because different federal, state, and local governments are working to address health issues. Health problems in the region are heightened by the high rates of poverty and the lack of health insurance coverage. According to a Behavioral Risk Factor Surveillance Survey (BRFSS) completed in 1996, 32.4\% of the population of El Paso County is uninsured. Among Hispanic residents, the rate of uninsured rises to $40 \%$ (Condon et al., 1997). Community clinics in the area provide care for both insured and uninsured members of the population, usually offering services on a sliding scale fee basis. Against this bleak background the Paso del Norte Health Foundation represents a key resource.

The Paso del Norte Health Foundation (PDNHF) was established in 1995 through the sale of a not-for-profit hospital in El Paso, Texas. The PDNHF mission is to improve public health through a focus on prevention and health promotion, generally working through community based organizations. The region served by the PDNHF includes El Paso, Texas (population 700,000), and Ciudad Juarez, Chihuahua, Mexico (population 1.2 million), which together make up the largest metropolitan area on the US-Mexico border. In addition, the PDNHF serves the areas of Doña Ana County, New Mexico and the sparsely populated counties of Otero, New Mexico and Hudspeth, Texas.

The Clinic Health Education and Lifestyle Promotion (Clinic HELP) Initiative, funded by the PDNHF, was designed to extend health education services to medically indigent residents along the US-Mexico border. A meeting of community health clinics was convened to discuss the goals of the initiative, and the procedures for clinic involvement. Ten agencies were invited to submit proposals which included a needs assessment, clinic objectives and a plan to meet those objectives. Nine of the ten sites were funded initially and a tenth clinic was added the following year. Funding was for one year, with the potential for up to four years of funding dependant upon approval by the 
PDNHF. At the time of funding, most area clinics did not have professional health educators and there was a lack of primary prevention services. The pool of well-trained health educators, especially those who were prepared to work in clinical settings, in the Paso del Norte area was small.

Each of the clinics hired health education specialists. These ten health educators included four bachelor level health educators, two masters prepared health educators, a masters prepared social worker, and three registered nurses (Hoke, Byrd, Kelly, Brandon, and Lang, 2002). A technical assistance team (TAT) provided support to both the health educators and the key clinic personnel on an individual consultative basis. The TAT also organized capacity-building workshops and presentations for the health educators, covering topics such as program planning, evaluation, specific disease related content, and maintenance of programs. During the third quarter of each project year, funded agencies were required to submit a report which was reviewed by the TAT. The TAT then made recommendations to the PDNHF for future funding.

This paper reports findings of the evaluation that examines the integration of the health education specialists into the clinics, and the quantity and quality of health education services delivered.

\section{Methods}

Following approval by the local university's Committee for the Protection of Human Subjects, data collection was begun using focus groups, interviews, and questionnaires.

\section{Data Collection}

A series of four focus groups was held in order to obtain information relevant to specific evaluation questions. One focus group was held with participating agency directors $(n=10$ representing nine clinics), one with members of the Technical Assistant Team (TAT), project director and program officer $(n=5)$, and two with health educators $(n=9)$ who were providers of services for the various projects. Key questions were developed to guide the discussions, which were tape recorded and transcribed. The investigators conducted thematic analysis. The interpreted narrative was returned to focus group members for their review and affirmation of the interpretations drawn from the narratives.

Individual clinic site visits and interviews were conducted with health educators, agency executives, first-line supervisors of health educators, various clinicians (doctors, nursepractitioners, physician assistants, nurses) clinical peers (social workers, other allied health practitioners) and community health workers (promotoras) who worked with or for the health educators in some settings. These guided interviews were conducted by two (2) project research assistants who were registered nurses and master's degree students. The interviews were tape recorded for later transcription and thematic analysis. The site visits also included observations of actual health education sessions.

\section{Measurement}

Integration into Clinic. Genograms, a tool to identify the informal pattern of relationships within an organization (McIlvain, Crabtree, Medder, Stange, and Miller, 1998), were used as a means to assess the position of health education within the organizational structure of the agency, the closeness of health education to decision makers, and the degree to which there were interpersonal barriers or facilitators to key decision makers in the clinic. The health educators were asked to complete a genogram based on their clinic's organizational chart, locate themselves on the chart, and to indicate whether they had positive, close positive, distant, conflictual or no relationships with other staff members. They were then asked to locate key decision makers related to patient care, personnel and health promotion and the most powerful people who could get things done. Health educators were interviewed regarding the nature of the relationships in the genogram and the impact of that on their practice.

\section{Quantity and Quality of Health Education Services.}

A service delivery report form was developed by the health educators during year two of the project and was piloted in year three. Several training sessions were held to assure that the 
health educators were comfortable using the forms and a set of frequently asked questions and responses was provided to them. Data reported here were gathered during the months of October 2000 to April 2001, during the third year of the project.

These reports were submitted monthly and included a categorization of individual services by level of prevention and specific activity, age/grade level, and service location (on or off site). Group activities (number of sessions and number of attendees) were reported by level of prevention and specific activity. Categories within primary prevention were physical activity, nutrition, tobacco, stress reduction, general health promotion, and an open category to be specified by the health educator. Secondary prevention categories included hypertension, cholesterol, blood sugar, breast cancer, Pap smears and an open category. Diabetes, hypertension, heart disease, asthma, obesity, cancer, and other were the categories for tertiary prevention. Also recorded were incoming referrals by source (professional, self, health educator), and professional referrals made.

In order to ascertain the work distribution in a typical week, the health educators recorded daily the hours or fractions of hours (to .25 hours) they spent on 22 activities over a four week period during year three. These reports were submitted weekly. Weekly totals for each category were computed and the totals for the four weeks of data collection were averaged. The health educators in consultation with the TAT chose activities included in the assessment tool during a yearly retreat. Prior to data collection graduate assistants reviewed this protocol with each health educator.

Clients $(n=74)$ who had participated in the observed group or individual education sessions completed, in English $(\mathrm{n}=23)$ or Spanish $(\mathrm{n}=$ 51), eight (8) indicators of patient satisfaction using a four point scale from strongly disagree (1) to strongly agree (4). Items included were that the information was understandable, the health educator was knowledgeable and able to answer my questions, the health educator was friendly and courteous, the other clinic staff was friendly and courteous, the location was convenient, the services were at a convenient time, they would recommend the services to family or friends, and the services met their needs. Also included was the format and topic of education, whether it was a first visit, the number of times they had seen the health educator, how they found out about the service, and the ways they learned best. The eight items were summed to create a satisfaction scale.

\section{Analysis}

Focus groups and interviews were tape-recorded and transcribed. Transcriptions were reviewed and the investigators and the research assistants coded the themes. After individual coding, the group reviewed the codes, discussed any differences, and then agreed to final codes. Themes were then transferred to a matrix in order to organize them by type of person interviewed (health educator, administrator, etc.).

Mean scores were used to describe the levels of patient and health educator satisfaction. Types of activities performed by the health educators were averaged over a seven-month period.

\section{Results}

\section{Integration of the health education specialists into the clinics}

The genogram analysis identified three major types of relationships: 1) the health educator reporting through community outreach channels to the agency executive director; 2) the health educator reporting directly to the medical director who reports to the agency director; or 3) the health educator reporting to an intermediary who then reports to the medical director who, in turn, reports to the agency director.

The health educators who reported services via the community stream indicated more difficulty integrating into the clinical setting than did those who reported under the medical director chain. The health educators who reported directly to the medical director or who were recognized as a separate entity under the community outreach channels, and therefore had access to their own funds, stated that they had more autonomy and 
experienced less frustration in trying to implement their programs. Conversely, and as would be anticipated, the individuals who reported that they did not have direct access to their funds indicated more frustration in implementing their programs than their peers.

An ally- not necessarily in the health educator's direct chain of command, but within their organization with whom they could discuss their program - was perceived to be beneficial by the health educators. Overall the health educators reported very limited numbers of negative interactions or conflictual relationships within their organizations.

A force field analysis (Bozak, 2002) of TAT focus group data was used to identify driving and restraining forces impacting the successful integration of health education activities into the clinical settings. As seen in Figure 1, a key driving force was the perception that managers of the contemporary health care system (including managed care) were supportive of a willingness to experiment with new approaches to wellness. Also, those of the ten Clinic HELP agencies that had previously experimented with the health education approach remembered the positive outcomes of those efforts and were supportive of reinitiating these ideals. An agency ally or program champion (another individual in the setting) who endorsed the importance of the role of the health educator was an asset to establishing and sustaining the budgeted position. Finally, health education activities could be used as a marketing strategy and services could be viewed as a positive quality improvement, adding value to continuous quality improvement plans relevant to agency accreditation.

\section{Clinic HELP Force Field}

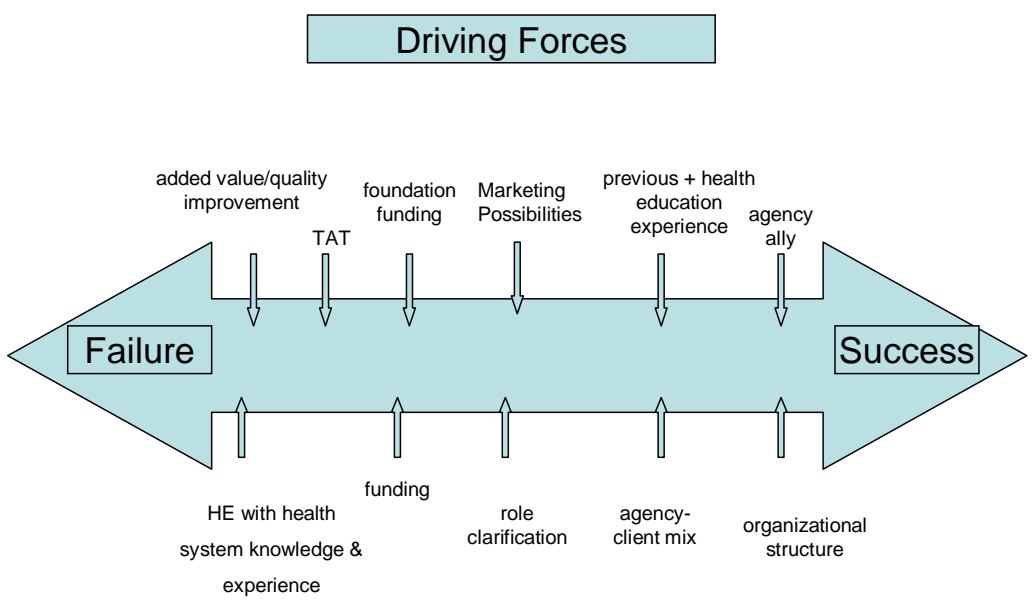

Restraining Forces

Figure 1

Clinic HELP Force Field

Notation: This figure shows the driving and restraining forces for health education integration into clinic settings. 
Restraining forces included the perception that some of the health educators may not have been fully aware about the constraints imposed by working within a medical system, e.g., quality assurance, documentation and scope of practice issues for a variety of health personnel. Another restraining force was a lack of clarity about role delineation and role definition. This included the limits of the health educator role and its interface with other health care provider roles, as well as the communication between health educators and other providers about this issue. Lack of funding was also seen as a restraining force. One respondent stated, "You can't expect these clinics...to get very serious about keeping a health educator after [project funding ends]...the funding isn't there in our system for this kind of care." Finally, it was acknowledged that a majority of participant clinics served a clientele that was more accustomed to using health care services on an episodic basis, and were less attuned to the use of health promotion services.

In discussing the integration of health education in the clinics over time, the TAT discussed the importance of "finding the niche", i.e., creating a best fit between a project and the individual who would assume responsibility to implement the project and promote its success. This "best fit" had as much to do with the needs of the clinic as it did with the skills and abilities of the health educator. For example, when discussing the large medical school based clinic, one TAT member commented:

"we tried ... the same way. . . we went through two sweet little health educators, who just couldn't do it. (Another speaker: "Who got chewed up.") And we sat down with them in a meeting and came to the conclusion that as the kind of clinic that (teaching hospital) it is, it's not a community-based clinic, it's a training ground for residents. It's a big, big university monster, and the kind of clientele that they serve are not really interested in lifestyle or in you know big health promotion, staying healthy messages, they're interested in getting well from whatever they're sick from."

Another TAT member discussed this issue in regard to the one volunteer clinic that was included in the project:

"In the case of a charitable clinic, we really tried to work with that person to find her niche and prove herself to be valuable within her environment, which is among a bunch of volunteer docs who are only occasionally there. . ... So we tried to help her develop a presentable program that would appeal to her boss as well as to most of the practitioners, and she began to accept referrals. And even there, that, though, quickly became unmanageable because she was overwhelmed with referrals and as one individual could not accommodate to all of the needs of the people being referred to her."

One indicator of integration into the clinics may be the pattern of referrals to the health educator. According to the health educator activity reports, about half of referrals $(50.6 \%)$ were from the health care provider, and far fewer $(10.6 \%)$ were self-referrals. Health educators themselves generated $38.9 \%$ of referrals.

\section{The quantity and description of} health education services delivery

The monthly service delivery report and worktime study provide a means of describing the quantity and types of health education services provided. 
Table 1

Average monthly number of client contacts by prevention focus

\begin{tabular}{|l|c|c|c|}
\hline \multicolumn{1}{|c|}{ Focus } & $\begin{array}{c}\text { Average number of } \\
\text { client contacts (SD) }\end{array}$ & $\begin{array}{c}\text { Average number } \\
\text { of health } \\
\text { education } \\
\text { sessions (SD) }\end{array}$ & $\begin{array}{c}\text { Average number of } \\
\text { attendees per health } \\
\text { education session (SD) }\end{array}$ \\
\hline Primary prevention & $303.3(73.9)$ & $23.7(5.2)$ & $19.6(4.5)$ \\
\hline Secondary prevention & $337.1(58.1)$ & $12.8(2.5)$ & $21.1(2.3)$ \\
\hline Tertiary prevention & $35.1(4.9)$ & $4.1(1.6)$ & $9.8(4.3)$ \\
\hline
\end{tabular}

The average numbers of client contacts and health education session and participants by level of prevention, averaged across seven months in the third year of the project, are presented in Table 1. There were almost twice as many primary as secondary prevention group sessions, with far fewer tertiary prevention sessions focused on general health promotion. The primary focus of both the secondary and tertiary prevention classes was diabetes $(33.1 \%$ and $34.2 \%$, respectively). The tertiary prevention groups had a smaller average number of attendees than the other two types of groups.

The largest number of client contacts was for secondary prevention, evenly divided among hypertension, Pap smear and blood glucose. The next largest category for client contacts was primary prevention with nutrition education accounting for $76 \%$ of the contacts. Tertiary prevention contacts averaged 35 per month (5.1\% of total contacts), with almost half being related to diabetes.

Services were provided to a full range of the population, including children and adults. Children aged 0-5 years accounted for $2.9 \%$ of the contacts; children in grades K-12, $13.2 \%$; adults aged 18-25, 16.5\%; adults aged 26-40, $32.6 \%$; those aged 41-64, 29.1\%; and those 65 years and older, $5.8 \%$. The majority of services $(72.4 \%)$ were provided at the agency site, while the remainder was provided at community sites such as schools, community centers, health fairs, and worksites.

The health educators indicated that the amount of contact with patients/clients had increased over time (i.e., patients were returning for services when previously they might have been lost to care) as a consequence of the increased recognition of the importance of health education services. Anecdotally, they reported positive changes in patient behaviors and outcomes (e.g., improved blood sugar levels following diabetes education; weight loss following diet guidance and nutrition information).

A work/time study was conducted in the attempt to demonstrate the proportion of work effort that health educators dedicated to specific role functions (Appendix A) presents the complete account of this analysis.

A snapshot of the typical workweek indicates that the health educators engaged in activities that directly support the agency (e.g., grant writing, providing staff in-service classes) for about two days of each workweek, with administrative duties and professional communication within the agency comprising about 3.5 hours each. Activities within the program planning, development and evaluation cycle for health education took an average of 8.5 hours weekly, with 3.2 of those being preparation for classes and consultations. The health educators provided direct service delivery for approximately one day per week, with 4.1 hours spent on average conducting classes. Community outreaching and networking, through interagency meetings and the provision of presentations and health fairs in the community, and clerical duties accounted for approximately half a day each. 


\section{Quality of Health Education Services}

The overarching perception of those who participated in the interview process (administrators, other health care providers, supervisors, and health educators) was that the activities in which the health educators engaged (conducting classes and consultations) was a significant step forward, when compared to the prior practice of distribution of printed materials and brochures.

Administrators viewed the health educator as a valuable resource within the clinics and also as a liaison with the community. One respondent stated "you realize that you really can work with youth in order to get families involved in health care" and pointed to the local school district's receptivity to the concepts of health promotion. Another said "We've found that providing that education to patients not only gives them a sense of responsibility for their health care, but also gives them a level of comfort in how to deal with their major diseases."

Providers, including physicians, nurses, and social workers reported that they found the health educator's role to be complementary to their own, and that the health educators were providing a necessary service. Providers often mentioned the health educator's ability to spend more time with the client than they were able to themselves. One Nurse practitioner said,

"It's very nice to know that there are extra resources that you can't always do a lot of teaching or everything in a 15 minute appointment, and it is good to know that there is definitely somebody that goes hand in hand. And you can hand this patient off to know that hey are being educated even though you can't do it at that point in time and they can do more extensive teaching than, you know, a fifteen minute appointment can allot."

Many seemed impressed by the quality of the program, and two of the physicians said that they had seen outcomes such as lower blood sugars and weight loss. One director of nursing said, "Sometimes the clinical staff has a tendency to lose perspective because they get caught up in treating the illness. But the education department is really good at reminding us, they remember, we could prevent some of this if we really tried. So it has played a key role in the care we give." On the other hand, a few expressed concern that the health educators might be practicing outside their content knowledge and beyond their competency levels.

\section{Client Satisfaction}

Clients responding to the satisfaction survey indicated they had participated in individual (2), group (66) or both (6) types of health education services. Provider referral to the classes was reported by $61.7 \%$ of the respondents; $29.8 \%$ were recommended to attend by a friend, and an additional $8.5 \%$ said they responded to a flyer. Over two-thirds reported they had received services from one to three times (68.8\%), 10.4\% from four to six times, and $20.8 \%$ more than six times.

Ratings for eight indicators of patient satisfaction are reported in Table 3. The mean scores demonstrated a high level of satisfaction in all areas, with scores of three or greater. The lowest score (3.0) related to presentation of information in an understandable way, and the highest scores (3.6) were for the summary items of meeting the client's needs and willingness to recommend the services to family and friends.

Choosing all that apply on a closed ended item, the majority of clients reported that they learned best through listening while attending classes $(\mathrm{n}=59)$, followed by reading written materials $(n=32)$, and visually, through watching videos or presentations $(n=29)$. Only 13 respondents indicated that they learned best through one-onone, individualized teaching sessions.

\section{Discussion and Recommendations}

Health education is increasingly emphasized in primary care, especially in managed care settings (Barnes, Neiger, Mondragon, Hanks, and Brandon, 2002). As health educators enter the workforce in clinical settings in greater numbers, better understanding of their integration into clinic operations and scope of practice is needed. The experience of the Clinic 
HELP initiative in community clinics and one

medical center provides insight into these issues.

Table 3

Patient satisfaction with health education

\begin{tabular}{|l|c|c|}
\hline \multicolumn{1}{|c|}{ Indicators of satisfaction } & \multicolumn{1}{|c|}{$\begin{array}{c}\text { N of } \\
\text { respondents }\end{array}$} & $\begin{array}{c}\text { Mean rating } \\
\text { (SD) }\end{array}$ \\
\hline The information was presented in an understandable manner & 72 & $3.61(.49)$ \\
\hline $\begin{array}{l}\text { The health educator was knowledgeable and able to answer } \\
\text { my questions }\end{array}$ & 72 & $3.69(.46)$ \\
\hline The health educator was friendly and courteous & 73 & $3.74(.44)$ \\
\hline Other clinic staff were friendly and courteous & 68 & $3.53(.56)$ \\
\hline The location of the services is convenient & 67 & $3.55(.53)$ \\
\hline I was able to receive services at a convenient time & 69 & $3.54(.50)$ \\
\hline I would recommend the services to my family and friends & 69 & $3.65(.48)$ \\
\hline The health education services met my needs & 68 & $3.62(.52)$ \\
\hline
\end{tabular}

Notation: 4-point scale from (1) strongly agree to (4) strongly disagree

In general, the Clinic HELP initiative was able to integrate at least some level of health education into the ten participating clinics. The degree to which this occurred depended on the clinic, the health educator, and the fit between the two. Mutual adaptation occurred as the health educators either developed or exploited a niche in the clinical environment, or left the job.

The roles taken by the health educators included those in the Certified Health Education Specialist competencies, including the masters' level competencies of administration and management. The competencies, however, do not address specific clinical issues such as maintenance of patient confidentiality, individual patient counseling, chart documentation, and relationships with other clinical providers. In addition, the competencies were not designed to include content knowledge, which is critical in clinical care settings. The scope of practice in clinical settings for health educators is often undefined, in contrast to that of licensed clinical providers. Three of the ten health educators in this project were registered nurses (3), enabling them to function more comfortably in the clinical setting. McKenzie (2004) has noted that health educators with clinical backgrounds are more comfortable working in clinical settings, and has suggested providing training for health educators in four settings; community, school, worksite and clinic.

When looking at Table 1, it appears that the majority of the health educators' work focused on secondary prevention; however, one of the projects had a mission dedicated to screening and was very productive in that domain. Therefore the average number of client contacts reported here for all participant agencies is somewhat inflated by the large numbers contributed by this one clinic. The emphasis on primary and secondary prevention messages, and the lesser focus on tertiary prevention, is consonant with the mission statements proposed by most of the agencies.

The tension felt between the project focus on primary prevention and the acute care/tertiary prevention practiced in clinical settings was an ongoing challenge. For example, this issue was evident in the teaching hospital clinic. Although two health educators tried to overcome this difference in focus, they were unable to do so, in part because the clinic served only ill patients and they were not as interested in primary prevention education. The TAT member that was assigned to the clinic met with the dean and the nursing supervisor responsible for the program and a decision was made to change the focus in that clinic to tertiary prevention. It was 
decided that the health educator could start with "illness" education and then gradually expand the program to include primary prevention for the patients, their families and the community at large. This tension was noted in other sites as well, depending on the client mix (primary, secondary or tertiary prevention desires) and type of services delivered at the clinic.

Clinical agencies should have a clear picture of the focus of their health education services and this should guide their selection of a health educator with the needed expertise clinical education, community outreach, lifestyle counseling).

Our findings on tasks performed by clinic health educators were similar to those found by Johnson et al. (2005) for health educators employed by public health agencies. The health educators in this project spent $21.2 \%$ of their time in program planning and evaluation compared to $19.6 \%$ by the public health workers. Implementation of health education services was similar with public health educators spending $21.2 \%$ of their time and our health educators spending $23 \%$ of their time in this activity.

The placement of health education in the agency was critical to the successful integration of the program. Those health educators who were in a direct line to the medical director, or who were part of a separate department of health education were more likely to report higher levels of integration. On the other hand, those who reported to entities outside of the clinic chain of command were most likely to feel frustrated with the level of integration into the clinic. For instance, one of the health educators reported to a supervisor who was not at the clinic site and whose main responsibility was to maintain grant funding for several clinics and to organize training for nursing and medical students in the clinic. This health educator reported feeling detached from the life of the clinic. Having a "place" in the clinic organizational chart for health education, even if that place is under the nursing or medical director, increases the integration of the service into the clinic.

As others have found (Stecker \& Goodman, 1989; Yeatman \& Nove, 2002), position within the organization which allows access to the organization leaders and having an ally or program champion within the organization was critical to the development and integration of the program into the clinic.

Most of the clinic administrators felt that the addition of health education to the clinic services added value for the clients and improved the quality of services provided. In addition, clients reported high levels of satisfaction with services provided by the health educators.

Funding can be seen as both a driving and a restraining force. This project began by fully funding clinics to incorporate health educators into their practice. The resulting increase in health education activities, patient satisfaction with services, and perceived added value laid the foundation for many agencies to redirect or seek other funding options to maintain a health educator on staff. Because in most clinics health education is not a directly reimbursable service, it is essential to have start-up funding to allow for generation of substantial outcomes in order to justify continuation of the service.

Integration of health education into a clinical setting is a complex undertaking and models to guide successful integration are limited. However, this project has shown that funding, appropriate training, guidance from a technical expert, clear expectations and having a strong program champion combined with health educator/health agency "fit" can facilitate the process.

\section{References}

Barnes, M. D., Neiger, B. L., Mondragon, D., Hanks, W. A., and Brandon, J. E. (2002). Expanded education roles in managed care: Relationships between CHES, HEDIS, and NCQA. Health Promotion Practice, 3, 43-49. 
Bozak, M. G. (2002). Using Lewins' force field analysis in implementing a nursing information system. CIN: Computers, Informatics, Nursing, 21(2), 80-85.

Condon, K., Pauli, A., Price, V., Fry, B., Kaigh, W., and Kaigh, G. (1997). El Paso health report. El Paso, TX: Paso del Norte Health Foundation.

Hoke, M. M., Byrd, T. L., Kelly, M. P., Brandon, J. E., and Lang, P. (2002). The clinic HELP initiative: promoting health education in primary care clinics. Health Promotion Practice, 3, 477-484.

Johnson, H. H., Glascoff, M. A., Lovelace, K., Bibeau, D. L., and Tyler, E. T. (2005). Assessment of public health educator practice: health educator responsibilities. Health Promotion Practice, 6, 8996.

McIlvain, H., Crabtree, B., Medder, J., Stange, K. C., and Miller, W. L. (1998). Using practice genograms to understand and describe practice configurations. Family Medicine, 30, 490-496.

McKenzie, J. F. (2004). Professional preparation: Is a generic health educator really possible? American Journal of Health Education, 35, 16-18.

Remington, P. L., Smith, M. Y., Williamson, D. F., Anda, R. F., Gentry, E. M., and Hogelin, G. C. (1988) Design, characteristics, and usefulness of state-based behavioral risk factor surveillance: 1981-87. Public Health Reports, 103, 366-375.

Steckler, A., and Goodman, R. M. (1989). How to institutionalize health promotion programs. American Journal of Health Promotion, 3(4), 4-43.

Yeatman, H. R., and Nove, T. (2002). Reorienting health services with capacity building: A case study of the core skills in health promotion project. Health Promotion International, 17, 341-350.

\section{Acknowledgements}

We would like to thank the Paso del Norte Health Foundation for their support of this project.

Author Information

Theresa L. Byrd, Dr. PH.

Associate Professor

Health Promotion \& Behavioral Sciences

Texas Houston of University

Nell H. Gottlieb, Ph.D.

Professor

Department of Kinesiology and Health Education

University of Texas at Austin

Mary M. Hoke, Ph.D., APRN-BC*

New Mexico State University

School of Nursing MSC 3185

PO Box 30001

Las Cruces, NM 88003-8001

Ph.: 505-646-7449

Fax.: 505 646-4356

E-Mail: $\underline{\text { mhoke@nmsu.edu }}$

* corresponding aruthor 


\section{Appendix A}

Clinic Help Time Study: Health Educators

\begin{tabular}{|c|c|c|c|}
\hline Activity (in hours) & $\begin{array}{l}\text { Week Total } \\
\text { Mean (SD) }\end{array}$ & $\begin{array}{l}\text { Week Total } \\
\text { Median }\end{array}$ & $\begin{array}{l}\text { Week Total } \\
\text { Range }\end{array}$ \\
\hline \multicolumn{4}{|l|}{ Direct Service Delivery } \\
\hline Teach classes & $4.1(3.7)$ & 4.0 & $0-14.8$ \\
\hline Individual patient consults & $2.2(2.1)$ & 1.9 & $0-7.0$ \\
\hline Home visits & $0.3(1.1)$ & 0.0 & $0-5.0$ \\
\hline Documentation in patient charts & $0.9(1.4)$ & 0.5 & $0-5.5$ \\
\hline \multicolumn{4}{|l|}{ Community Outreach and Networking } \\
\hline $\begin{array}{l}\text { Attend inter-agency meetings or } \\
\text { conferences }\end{array}$ & $2.5(3.8)$ & 1.0 & $0-17.0$ \\
\hline $\begin{array}{l}\text { Providing community outreach (talks, } \\
\text { health fairs, etc) }\end{array}$ & $1.7(2.2)$ & 1.4 & $0-10.0$ \\
\hline \multicolumn{4}{|l|}{ Activities Supporting Agency } \\
\hline $\begin{array}{l}\text { Professional communication within the } \\
\text { agency (consults, emails, memos, one } \\
\text { on one meetings) }\end{array}$ & $3.4(2.5)$ & 2.9 & $0-12.8$ \\
\hline Attend meetings within the agency & $0.9(1.5)$ & 0.0 & $0-7.5$ \\
\hline $\begin{array}{l}\text { Providing in-services/ education to } \\
\text { clinic staff }\end{array}$ & $1.1(2.9)$ & 0.0 & $0-12.0$ \\
\hline Administrative duties & $3.8(3.3)$ & 3.5 & $0-12.0$ \\
\hline Management/ supervising other staff & $1.1(1.9)$ & 0.0 & $0-8.0$ \\
\hline Supervising/ precepting interns & $0.8(1.3)$ & 0.0 & $0-4.0$ \\
\hline Completing reports & $1.9(2.0)$ & 1.4 & $0-8.0$ \\
\hline Grant writing & $1.0(2.2)$ & 0.0 & $0-10.0$ \\
\hline Attending trainings & $0.8(1.7)$ & 0.0 & $0-7.0$ \\
\hline \multicolumn{4}{|l|}{$\begin{array}{l}\text { Plan, Develop and Evaluate Health Education } \\
\text { Programming }\end{array}$} \\
\hline Research/ prepare classes and consults & $3.2(2.8)$ & 2.5 & $0-13.0$ \\
\hline $\begin{array}{l}\text { Preparing/ creating patient brochures } \\
\text { and other teaching materials }\end{array}$ & $2.3(4.6)$ & 1.3 & $0-23.8$ \\
\hline Evaluating programs/ data analysis & $1.5(2.8)$ & 0.0 & $0-14.5$ \\
\hline Program development/ improvement & $1.5(1.9)$ & 1.0 & $0-8.8$ \\
\hline
\end{tabular}

